\title{
Planos de Nutrição para Leitoas com Alto Potencial Genético para Deposição de Carne Magra dos 65 aos $105 \mathrm{~kg}$
}

\author{
João Luís Kill2, Juarez Lopes Donzele ${ }^{3}$, Rita Flávia Miranda de Oliveira ${ }^{3}$, \\ Aloízio Soares Ferreira ${ }^{3}$, Darci Clementino Lopes ${ }^{3}$, Francisco Carlos de Oliveira Silva ${ }^{4}$, \\ Marcos Vinícius Gualberto Barbosa da Silva ${ }^{5}$
}

\begin{abstract}
RESUMO - Para avaliar o efeito dos planos de nutrição, com base em níveis de lisina, sobre o desempenho e as características de carcaça de leitoas em terminação, utilizaram-se 96 leitoas híbridas comerciais de alto potencial genético para deposição de carne magra, com peso médio inicial de 65,93 \pm 2,78 kg e final de 105,50 \pm 2,18 kg. Os animais foram distribuídos em um delineamento experimental de blocos ao acaso, com quatro tratamentos (planos de nutrição), doze repetições e dois animais por baia, considerada a unidade experimental. Os tratamentos consistiram de planos nutricionais (estabelecidos por níveis seqüenciais de lisina) para duas diferentes faixas de peso, 65 a $95 \mathrm{~kg}$ e 95 a $105 \mathrm{~kg}$. As rações foram isoenergéticas e os níveis de lisina foram obtidos variando a proporção entre o milho e o farelo de soja da ração. Não foi observado efeito dos tratamentos sobre o ganho de peso diário e sobre o consumo de ração diário. Houve efeito dos planos de nutrição sobre a conversão alimentar, sendo que o plano 3 propiciou melhora de 7,86\% em relação ao plano 1, não diferindo dos demais. O consumo de lisina aumentou de acordo com a elevação dos níveis de lisina dos planos de nutrição. No plano 4, o consumo de lisina foi superior em 25,43\%, em relação aos demais planos. Não houve diferença dos planos de nutrição sobre a taxa de conversão em músculo, conversão alimentar em músculo, comprimento de carcaça, espessura de toucinho na região entre a última e a penúltima vértebra lombar, a espessura de toucinho a $6,5 \mathrm{~cm}$ da linha dorso-lombar $\left(\mathrm{P}_{2}\right)$, o rendimento de carcaça, o rendimento de carne magra, o rendimento de gordura e sobre o rendimento de pernil. O estudo da análise econômica indicou que o plano de nutrição 2 , proporcionou o melhor retorno econômico sobre o custo da ração. Portanto, conclui-se que o plano de nutrição 3 (1,00 - 0,90\% de lisina) proporcionou os melhores resultados de desempenho e características de carcaça.
\end{abstract}

Palavras-chave: lisina, fase de crescimento, desempenho, genótipo

\section{Nutrition Plans for Gilts with High Genetic Potential for Lean Meat Gain from 65 to $105 \mathrm{~kg}$}

\begin{abstract}
Ninety and six crossbred gilts with high genetic potential for lean meat gain, with average initial weight of $65.93 \pm$ $2.78 \mathrm{~kg}$ and final weight of $105.50 \pm 2.18 \mathrm{~kg}$, were used to evaluate the effect of nutrition plans, based on the effects of lysine levels on the carcass traits of gilts in the finishing phase. A randomized block design, with four treatments, 12 replicates and two animals per box, used as experimental unit, was used. The treatments were constituted of nutritional plans (established by sequential lysine levels) for two different weights, from 65 to $95 \mathrm{~kg}$ and from 95 to $105 \mathrm{~kg}$. The isoenergy diets and the lysine levels were obtained by changes on dietary corn and soybean proportion. There was no effect of treatments on daily weight gain and daily feed intake. There was effect of nutrition plans on feed:gain ratio, and the nutrition plan 3 showed an increase of $7.86 \%$ in relation to nutrition plan 1 and did not differ from the others. Lysine intake increased as the lysine levels of nutrition plans increased. In the nutrition plan 4, lysine intake was $25.43 \%$ higher than the other plans. There was no significant difference of nutrition plans on muscle growth ratio, muscle feed:gain ratio, carcass length, backfat thickness in the region between the last and last but one lumbar vertebra, backfat thickness at $6.5 \mathrm{~cm}$ from the midline carcass, carcass yield, lean meat yield, fat yield and ham yield. By economic analysis, the nutrition plan 2 showed the best economic return on feed intake. It can be concluded that the nutrition plan 3 (1.00-0.90\% lysine) showed the best results of performance and carcass characteristics.
\end{abstract}

Key Words: lysine, genotype, performance, growing phase

\section{Introdução}

Fatores como sistemas de alimentação, capacidade genética, sexo, saúde, temperatura ambiente, en- tre outros, influenciam o requerimento de lisina nas diferentes fases do ciclo produtivo dos suínos.

As exigências de lisina, de fêmeas suínas, para maximizar as taxas e a eficiência de ganho, são

\footnotetext{
${ }^{1}$ Parte da tese de Doutorado apresentada à UFV. Financiada pela FAPEMIG.

2 Professor da UVV. E.mail: jlkill@ig.com.br

3 Professor do DZO/UFV. E.mail: donzele@mail.ufv.br

${ }^{4}$ Pesquisador EPAMIG.

${ }^{5}$ Pesquisador da Embrapa Gado de Leite.
} 
maiores do que as de machos castrados (Cromwell et al., 1993), além de apresentarem carcaça de superior qualidade comercial (Saenz, 1994). Tais diferenças são resultantes de mudanças endócrinas ocorridas durante todo o desenvolvimento sexual (Bellaver \& Viola, 1997).

A utilização de suínos híbridos comerciais, de alto potencial genético, é importante para obtenção de progênies, que apresentam carcaças magras com maior quantidade de carne. Diversas pesquisas, como as de Stahly et al. (1993), Friesen et al. (1994) e Wagner et al. (1999), entre outras, mostraram que suínos de sexos diferentes e provenientes de diferentes grupos genéticos não possuem as mesmas capacidades de deposição de carne e gordura, sendo que o aumento no nível de proteína na ração resulta em maior acúmulo de tecido muscular e menor deposição de gordura na carcaça. Assim, suínos com alta taxa de ganho protéico exigem maior consumo de aminoácidos, principalmente lisina, para que possam exteriorizar todo seu potencial genético.

A criação por sexo separado permite determinar as diferenças nas exigências nutricionais e, nesse sentido, prover vantagens econômicas aos produtores. Portanto, é importante avaliar as necessidades nutricionais, principalmente de lisina, para animais dentro de cada sexo e de acordo com o seu potencial genético para produção de carne magra na carcaça.

O objetivo deste trabalho foi avaliar o efeito de diferentes planos de nutrição, em função dos níveis de lisina da ração, para leitoas com alto potencial genético para deposição de carne magra, dos 65 aos 105 kg.

\section{Material e Métodos}

O experimento foi conduzido nas instalações da granja de melhoramento genético do Departamento de Zootecnia da Universidade Federal de Viçosa, localizada no município de Viçosa, Minas Gerais

Foram utilizadas 96 leitoas híbridas comerciais, selecionadas geneticamente para produção de carne magra, com peso médio inicial de 65,9 $\pm 2,78 \mathrm{~kg}$, distribuídas em delineamento experimental de blocos ao acaso, com quatro tratamentos (planos de nutrição), doze repetições e dois animais por baia, que foi considerada a unidade experimental. Para a distribuição dos animais dentro de cada bloco adotou-se, como critério, o peso inicial e o parentesco dos animais. Os blocos foram formados no tempo.

As rações experimentais foram formuladas à base de milho e farelo de soja, com $3.437 \mathrm{kcal} / \mathrm{kg}$ de energia digestível (ED), para atender as exigências dos animais, segundo Rostagno et al. (1992); com exceção da lisina que variou de acordo com a proporção de milho e farelo de soja da ração, resultando em rações com 0,$70 ; 0,80 ; 0,90$ e $1,00 \%$ de lisina total.

Cada plano de nutrição foi dividido em duas fases: terminação I - 65 a 95 kg e terminação II - 95 a $105 \mathrm{~kg}$, identificados em função do nível de lisina utilizado em cada ração, conforme mostrado na Tabela 1 .

As composições centesimal e química das rações experimentais, são apresentadas na Tabela 2. O fornecimento de ração e água foi à vontade.

As rações foram pesadas semanalmente e os animais foram pesados no início e no final do experimento, quando atingiram os pesos médios de 95,3 \pm $1,12 \mathrm{~kg}$ e $105,5 \pm 2,18 \mathrm{~kg}$, para as fases I e II, respectivamente, para a determinação do consumo de ração, ganho de peso, consumo de lisina e conversão alimentar.

Os animais foram alojados em baias equipadas com comedouros semi-automáticos e bebedouros tipo chupeta, no interior de um galpão com piso de concreto e cobertura de cimento amianto. Para registrar a temperatura diária foi utilizado termômetro de máxima e mínima colocado no interior do galpão.

Ao atingirem o peso de abate, doze animais, por tratamento, foram abatidos após jejum alimentar de 24 horas e de água nas últimas 12 horas. O abate foi feito por insensibilização e sangramento e, em seguida, depilados com lança chamas e eviscerados.

As carcaças inteiras, incluindo pés e cabeça, foram pesadas em balança eletrônica. As carcaças foram serradas, longitudinalmente, ao longo da colu-

Tabela 1 - Planos de nutrição de acordo com as fases de crescimento dos animais

Table 1 - Nutrition plans according to the animals growth phase

\begin{tabular}{|c|c|c|}
\hline \multirow[t]{2}{*}{$\begin{array}{l}\text { Planos de nutrição } \\
\text { Nutrition plans }\end{array}$} & \multicolumn{2}{|c|}{$\begin{array}{l}\text { Fases } \\
\text { Phases }\end{array}$} \\
\hline & $\begin{array}{l}\text { Terminação } \\
\text { I - } 65 \text { a } 95 \text { kg } \\
\text { \% Lisina } \\
\text { \% Lysine }\end{array}$ & $\begin{array}{c}\text { Terminação } \\
\text { II - } 95 \text { a } 105 \text { kg } \\
\text { \% Lisina } \\
\text { \% Lysine }\end{array}$ \\
\hline PLANO 1 & 0,80 & 0,70 \\
\hline PLANO 2 & 0,90 & 0,80 \\
\hline PLANO3 & 1,00 & 0,90 \\
\hline PLANO 4 & 1,10 & 1,00 \\
\hline
\end{tabular}


Tabela 2 - Composição centesimal, química e energética das rações experimentais que compõem os planos de nutrição

Table 2 - Percent, chemical and energetic composition of experimental diets fed in the nutrition plans

\begin{tabular}{|c|c|c|c|c|c|}
\hline \multirow[t]{2}{*}{$\begin{array}{l}\text { Ingredientes (\%) } \\
\text { Ingredients }\end{array}$} & \multicolumn{5}{|c|}{$\begin{array}{l}\text { Níveis de lisina (\%) } \\
\text { Lysine levels }\end{array}$} \\
\hline & 0,700 & 0,800 & 0,900 & 1,000 & 1,100 \\
\hline $\begin{array}{l}\text { Milho } \\
\text { Corn }\end{array}$ & 77,07 & 73,00 & 68,94 & 65,04 & 60,77 \\
\hline $\begin{array}{l}\text { Farelo de soja } \\
\text { Soybean meal }\end{array}$ & 17,12 & 20,89 & 24,70 & 28,30 & 32,26 \\
\hline $\begin{array}{l}\text { Fosfato bicálcico } \\
\text { Dicalcium phosphate }\end{array}$ & 2,05 & 2,05 & 2,06 & 2,05 & 2,06 \\
\hline $\begin{array}{l}\text { Calcário } \\
\text { Limestone }\end{array}$ & 1,10 & 1,10 & 1,05 & 1,05 & 1,05 \\
\hline $\begin{array}{l}\text { Óleo vegetal } \\
\text { Vegetal oil }\end{array}$ & 1,60 & 1,90 & 2,20 & 2,50 & 2,80 \\
\hline $\begin{array}{l}\text { Sal comum } \\
\text { Salt }\end{array}$ & 0,40 & 0,40 & 0,40 & 0,40 & 0,40 \\
\hline $\begin{array}{l}\text { Suplemento mineral } \\
\text { Mineral supplement }^{1}\end{array}$ & 0,25 & 0,25 & 0,25 & 0,25 & 0,25 \\
\hline $\begin{array}{l}\text { Suplemento vitamínico }{ }^{2} \\
\text { Vitamin supplement }\end{array}$ & 0,35 & 0,35 & 0,35 & 0,35 & 0,35 \\
\hline $\begin{array}{l}\text { Antibiótico } \\
\text { Antibiotic }\end{array}$ & 0,05 & 0,05 & 0,05 & 0,05 & 0,05 \\
\hline $\begin{array}{l}\text { Antioxidante (BHT) } \\
\text { Antioxidant } \\
\text { Composição calculada } \\
\text { Calculated composition }\end{array}$ & 0,01 & 0,01 & 0,01 & 0,01 & 0,01 \\
\hline $\begin{array}{l}\text { Proteína bruta }(\%) \\
\text { Crude protein }\end{array}$ & 14,20 & 15,60 & 17,00 & 18,38 & 19,82 \\
\hline $\begin{array}{l}\text { Energia digestível (kcal/kg) } \\
\text { Digestible energy }\end{array}$ & 3437 & 3437 & 3437 & 3437 & 3437 \\
\hline $\begin{array}{l}\text { Lisina total }(\%) \\
\text { Total lysine }\end{array}$ & 0,700 & 0,800 & 0,900 & 1,000 & 1,100 \\
\hline $\begin{array}{l}\text { Met }+ \text { cis total }(\%) \\
\text { Total Met }+ \text { Cys }\end{array}$ & 0,499 & 0,536 & 0,572 & 0,609 & 0,645 \\
\hline $\begin{array}{l}\text { Treonina total }(\%) \\
\text { Total threonine }\end{array}$ & 0,570 & 0,624 & 0,679 & 0,733 & 0,787 \\
\hline $\begin{array}{l}\text { Triptofano total (\%) } \\
\text { Total tryptophan }\end{array}$ & 0,180 & 0,203 & 0,226 & 0,249 & 0,271 \\
\hline $\begin{array}{l}\text { Cálcio (\%) } \\
\text { Calcium }\end{array}$ & 0,985 & 0,985 & 0,985 & 0,985 & 0,985 \\
\hline $\begin{array}{l}\text { Fósforo disponível (\%) } \\
\text { Available phosphorus }\end{array}$ & 0,498 & 0,498 & 0,498 & 0,498 & 0,498 \\
\hline
\end{tabular}

${ }^{1}$ Cada kg contém (Each kg of product contain): Co, 185 mg; Cu, 36450 mg; Fe, 57759 mg; I, 1470 mg; Mn, 41850 mg; Zn, 109499 mg.

${ }^{2}$ Cada $\mathrm{kg}$ contém (Each $\mathrm{kg}$ of product contain): ácido fólico, $351,75 \mathrm{mg}$; ácido pantotênico, $3500 \mathrm{mg}$; antioxidante, $1500 \mathrm{mg} ;$ biotina, $63 \mathrm{mg}$; colina, 52,5 g; niacina, 6930 mg; piridoxina, 630 mg; riboflavina, 1400 mg; selênio, 131,25 mg; tiamina, 350 mg; vit. A, 1750000 U.I./kg; vit. $B_{12}, 8750,70 \mathrm{mcg}$; vit. $D_{3}, 700000$ U.I./kg; vit. E, 3500 mg; vit. K, 700 mg.

${ }^{3}$ Bacitracina de zinco.

na vertebral e, posteriormente, as meias carcaças foram pesadas (separadamente). A cauda, por convenção, foi mantida na meia-carcaça esquerda, que foi usada para a determinação das medidas lineares de carcaça logo após serem serradas, e para o espostejamento, após permanecerem em câmara fria $\left(4\right.$ a $\left.8^{\circ} \mathrm{C}\right)$ por 24 horas.

Para o espostejamento foram utilizadas quatro meias carcaças (esquerda) provenientes de cada tratamento.
As medidas de comprimento de carcaça, rendimento de carcaça e área de olho de lombo foram avaliadas utilizando a metodologia descrita pela ABCS (1973). A espessura de toucinho, na região entre a última e a penúltima vértebra lombar; a espessura de toucinho a 6,5 cm da linha dorso-lombar (P2) e os rendimentos de carne magra (expressos pelo peso total de carne na carcaça em relação ao peso total da carcaça dissecada), de gordura (expressos como 
peso da gordura total da carcaça em relação ao peso da meia carcaça resfriada) e de pernil (expressos como porcentual do peso total do pernil em relação ao peso da meia-carcaça resfriada) foram realizados segundo as técnicas utilizadas pela indústria brasileira.

Para avaliação da taxa de crescimento em músculo (TCM) e conversão alimentar em músculo (CAM), foram usados o peso médio inicial (PMI) e peso médio final (PMF) dos animais, peso da carcaça quente (PCQ), peso médio da meia carcaça esquerda (PMCE), peso médio da meia carcaça esquerda fria (PMCEF), rendimento de carne magra (RCM), rendimento de carcaça (RC) e rendimento de frigorificação (RF).

A determinação do RC e RF foi realizado de acordo com a seguintes expressões:

$$
\begin{gathered}
\mathrm{RC}=\mathrm{PCQ} / \mathrm{PMF} \times 100 \\
\mathrm{RF}=\mathrm{PMCEF} / \mathrm{PMCE} \times 100
\end{gathered}
$$

Os cálculos de TCM e CAM foram feitos utilizando-se as expressões sugeridas por FOWLER et al. (1976):

$\mathrm{TCM}=(\mathrm{MFT}-\mathrm{MIT}) / \mathrm{PE}$

$\mathrm{CAM}=\mathrm{CA} /(\mathrm{RC} \times \mathrm{RF} \times \mathrm{RCM}) \times 10^{-6}$ em que: MFT (músculo no final do teste) $=$ PMF $x$ RC x RF x RCM x 10-6; MIT (músculo no início do teste) $=0,418 \times$ PMI (lb) - 3,650, de acordo com NPPC (1991) citado por ELLIS (1998); e PE = duração do período experimental.

Análise econômica

A análise econômica foi feita utilizando-se o conceito de índice de rentabilidade (IR) ou rentabilidade simples (BUARQUE, 1991). O IR foi determinado de acordo com a seguinte expressão:

$$
I R=\left(\sum_{i=1}^{n} Y i \times P-\sum_{i=1}^{n} C O N R i \times P R i\right) / \sum_{i=1}^{n} C O N R i \times P R i
$$

em que: IR = índice de rentabilidade; $\mathrm{Yi}=$ preço do animal no tratamento i; $\mathrm{P}$ = preço por $\mathrm{kg}$ do animal; CONRi $=$ consumo de ração no tratamento $\mathrm{i}$; e PRi = preço do kg da ração do tratamento i

Os preços utilizados na determinação dos custos das rações foram fornecidos por uma empresa comercial. Quanto aos preços dos suínos, foram usados os recebidos pelo produtor na granja, no período de janeiro a fevereiro de 1999.

As variáveis estudadas foram analisadas utilizando-se os procedimentos GLM do pacote estatístico SAS (1985).

As médias dos planos de nutrição foram testadas utilizando-se o teste F, por meio de funções lineares estimáveis (Contraste).

\section{Resultados e Discussão}

As médias das temperaturas mínimas e máximas, registradas durante todo o período experimental, foram, respectivamente, $23,7 \pm 1,63^{\circ} \mathrm{C}$ e $27,8 \pm 2,26^{\circ} \mathrm{C}$.

Os resultados de ganho de peso diário, consumo de ração diário, conversão alimentar, consumo de lisina diário, da taxa de conversão em músculo e de conversão alimentar em músculo são apresentados na Tabela 3.

Não se observou efeito $(\mathrm{P}>0,05)$ dos planos de nutrição sobre o ganho de peso médio diário (GPD) dos animais. Este resultado foi semelhante ao verificado por Johnston et al. (1993), Gomes (1998), Witte et al. (2000) e Oliveira (2001), que não constataram influência dos diferentes planos de nutrição, com base em níveis de lisina sobre o ganho de peso de suínos de 59 a 120 kg, 80 a 100 kg, 90 a 126 kg e 95 a $110 \mathrm{~kg}$, respectivamente. O mesmo foi verificado por outros autores (Marinho, 1990; Cromwell et al., 1993; Donzele et al., 1994; Friense et al., 1994; Pímenta, 1995), que também não constataram efeito do nível de lisina sobre o GPD de suínos em terminação.

Por outro lado, em estudos conduzidos por Lawrence et al (1994), Friesen et al. (1995), Hahn et al. (1995), Yen et al. (1996) e Souza (1997), foi verificada variação no ganho de peso dos suínos em terminação, em razão do aumento do nível de lisina da ração.

A divergência de resultados, observada entre os trabalhos, pode estar possivelmente relacionada, entre outros fatores, à diferença nos genótipos dos animais utilizados, bem como ao ambiente térmico. A temperatura registrada durante a condução deste trabalho ficou acima da faixa de termoneutralidade proposta por Silva (1999), para animais na fase de crescimento-terminação (65 a 105 kg).

Segundo recomendações do NRC (1998), a exigência de lisina, de leitoas na fase de terminação (80 a 120 kg), varia de 0,60 para 0,69\%, em função da diferença no potencial de ganho diário em carne dos animais.

O consumo de ração médio diário (CRD) não foi influenciado pelos planos de nutrição. Da mesma forma, Cofeey et al. (1994), Friense et al. (1995), Fontes (1999) e Cline et al. (2000) não constataram diferenças no consumo de ração de leitoas na fase de terminação, recebendo ração com níveis crescentes de lisina.

Considerando os resultados obtidos por Chen et al. (1999), em que ficou evidenciado que o excessivo 
Tabela 3 - Valores médios obtidos de desempenho e consumo de lisina de leitoas com alto potencial genético para deposição de carne magra, dos 65 aos $105 \mathrm{~kg}$ de peso, em função dos planos de nutrição

Table 3 - Average values of performance and lysine intake of gilts with high genetic potential for lean meat from 65 to $105 \mathrm{~kg}$, according to the nutrition plans

\begin{tabular}{|c|c|c|c|c|c|}
\hline \multirow[b]{2}{*}{$\begin{array}{l}\text { Parâmetro } \\
\text { Parameter }\end{array}$} & \multicolumn{4}{|c|}{$\begin{array}{c}\text { Planos de nutrição (níveis de lisina, \%) } \\
\text { Nutrition plans - lysine levels }\end{array}$} & \multirow[b]{2}{*}{$\begin{array}{l}\mathrm{CV} \\
\%\end{array}$} \\
\hline & $\begin{array}{c}1 \\
(0,80-0,70)\end{array}$ & $\begin{array}{c}2 \\
(0,90-0,80)\end{array}$ & $\begin{array}{c}3 \\
(1,00-0,90)\end{array}$ & $\begin{array}{c}4 \\
(1,10-1,00)\end{array}$ & \\
\hline $\begin{array}{l}\text { Ganho de peso diário (g) } \\
\text { Daily weight gain }\end{array}$ & 961 & 971 & 962 & 977 & 5,94 \\
\hline $\begin{array}{l}\text { Consumo de ração diário (g) } \\
\text { Daily feed intake }\end{array}$ & 2690 & 2565 & 2482 & 2599 & 8,17 \\
\hline $\begin{array}{l}\text { Conversão alimentar }{ }^{1} \\
\text { Feed:gain ratio }\end{array}$ & $2,80^{\mathrm{a}}$ & $2,65^{a b}$ & $2,58^{\mathrm{b}}$ & $2,67^{\mathrm{ab}}$ & 7,03 \\
\hline $\begin{array}{l}\text { Consumo de lisina diário }(\mathrm{g})^{1} \\
\text { Daily lysine intake }\end{array}$ & $20,79^{c}$ & $22,39^{\mathrm{bc}}$ & $24,16^{\mathrm{b}}$ & $27,88^{\mathrm{a}}$ & 7,95 \\
\hline $\begin{array}{l}\text { Taxa de crescimento em músculo }(\mathrm{g} / \mathrm{d}) \\
\text { Muscle growth rate }\end{array}$ & 482 & 484 & 498 & 476 & 5,13 \\
\hline $\begin{array}{l}\text { Conversão alimentar em músculo } \\
\text { Muscle feed:gain ratio }\end{array}$ & 6,01 & 5,59 & 5,63 & 5,68 & 5,26 \\
\hline
\end{tabular}

${ }_{1}^{1}$ Médias seguidas por letras diferentes, na mesma linha, diferem pelo teste $F(P<0,05)$.

Means within a row followed by the different letters differ $(P<.05)$ by $F$ test.

fornecimento de proteína reduz o ganho de peso e o consumo de ração diário dos suínos em terminação, e que este efeito é mais pronunciado em fêmeas, pode-se deduzir, com base nos resultados de ganho de peso e consumo de ração diário verificados neste trabalho, que os maiores níveis de lisina avaliados não se caracterizaram como excessivamente altos.

Houve efeito $(\mathrm{P}<0,01)$ dos planos de nutrição sobre a conversão alimentar (CA), sendo que os animais que receberam o plano de nutrição 3 , em que se utilizaram os níveis 1,00 e 0,90\% de lisina, apresentaram melhora de $7,86 \%$ na $\mathrm{CA}$, em relação àqueles que receberam o plano 1 , em que foram utilizados os níveis de 0,80 e $0,70 \%$ de lisina total. Já os animais que receberam os planos de nutrição 2 e 4 apresentaram valores intermediários de conversão alimentar, que não diferiram entre si e nem dos demais tratamentos.

Este resultado está em acordo com o obtido por Fontes (1999), que, utilizando leitoas de 60 a $95 \mathrm{~kg}$, verificou melhor valor de CA no nível de 1,00\% de lisina total; divergindo do encontrado por Friesen et al. (1995), que observaram melhora linear na eficiência alimentar de leitoas dos 72,5 a 104 kg, em razão do aumento de 0,62 a 1,13\% no nível de lisina da ração. Efeito positivo dos níveis de lisina da ração sobre a eficiência de utilização do alimento para ganho de peso, em suínos na fase de terminação, abatidos com peso superior a $100 \mathrm{~kg}$, é demonstrado por vários autores (Cromwell et al., 1993; Friesen et al., 1995; Dourmad et al., 1997; Souza, 1997;
Loughmiller et al., 1998; King et al., 2000; Witte et al., 2000; Oliveira, 2001).

A melhora ocorrida na CA entre os planos de nutrição 1 e 3, estaria indicando uma possível alteração na composição do ganho com aumento na deposição de proteína e redução na deposição de gordura na carcaça. Embora possa resultar em menor eficiência energética de ganho (Chen et al., 1999), a alteração na composição do ganho leva a uma melhora na eficiência de utilização do alimento por unidade de ganho de peso (Hahn et al., 1995), pelo fato de que, na deposição de tecido protéico, ocorre, simultaneamente, maior deposição de água, contrariamente à deposição de tecido adiposo.

Estas prováveis mudanças teriam ocorrido em razão da diminuição calculada de $7,3 \%$ no consumo de energia metabolizável e do aumento $(\mathrm{P}<0,01)$ de 16,2\% do consumo de lisina médio diário (CLD) verificados entre aqueles tratamentos.

Com os resultados obtidos, ficou evidenciado que a exigência de lisina para melhor resposta de CA, de leitoas na fase de terminação, é maior que aquele para ganho de peso, o que também foi constatado por Chen et al. (1999).

Os planos de nutrição influenciaram $(\mathrm{P}<0,01) \mathrm{o}$ CLD, com os animais que receberam o plano 4, apresentando o maior consumo. Da mesma forma, Gomes (1998) constatou variação no consumo de lisina em função dos diferentes níveis de lisina nos planos nutricionais avaliados. 
O consumo médio diário de 24,16 g de lisina total, correspondente ao consumo calculado de 21,14 g de lisina digestível, verificado no plano de nutrição 3, no qual se obteve a melhor resposta de CA, evidenciou que as recomendações de 18,4 e 17,0 g de lisina digestível diário, respectivamente, para leitoas de 50 a $80 \mathrm{~kg}$ e de 80 a $120 \mathrm{~kg}$, de alto potencial de ganho de carne, preconizadas pelo NRC (1998), não atendem às exigências desses animais para melhor eficiência de ganho de peso.

Não se observou efeito dos tratamentos sobre a taxa de crescimento em músculo (TCM) e sobre a conversão alimentar em músculo (CAM), o que está em acordo com os dados de Pimenta et al. (1995) e Gomes (1998). Por outro lado, Coffey et al. (1994), apesar de não encontrarem diferença na TCM de leitoas em terminação, verificaram aumento de $12 \%$, quando o nível de lisina aumentou de 0,58 para $0,80 \%$; enquanto Oliveira (2001), utilizando suínos machos castrados com alto potencial genético para deposição de carne magra na carcaça, dos 95 aos 110 kg, constatou melhora linear na CAM com o aumento do nível de lisina da ração, de 0,50 para 0,79\%.

O valor médio da CAM, de 5,73, obtido neste trabalho, ficou abaixo dos valores 7,26, 7,12 e 6,72 encontrados, respectivamente, por Campabadal \& Navarro (1997), Gonçalves et al. (1999) e Oliveira (2001), trabalhando com suínos machos castrados dos 22 aos $109 \mathrm{~kg}$; dos 30 aos $130 \mathrm{~kg}$, e dos 95 aos $110 \mathrm{~kg}$, respectivamente.

A diferença nos valores de CAM, encontrados entre os trabalhos, pode ser parcialmente explicada pelo sexo e pelas diferenças genéticas entre os animais utilizados. De acordo com Chen et al. (1999), suínos com elevada capacidade de deposição de carne magra na carcaça possuem maior eficiência de utilização do alimento, produzindo carcaças com mais músculo e menos gordura, quando comparados com animais de baixo potencial genético para deposição de carne magra.

Os resultados das avaliações das características de carcaça das leitoas aos 105 kg em função dos planos de nutrição, são apresentados na Tabela 4.

Não foi observado efeito dos planos de nutrição sobre o comprimento de carcaça (CCMB) e sobre o rendimento de carcaça (RC), o que está em acordo com as observações de Friesen et al. (1994), Hernández Villareal (1996) e Gomes (1998). De acordo com Gomes (1998), o consumo de lisina tem pouca ou nenhuma influência sobre as característi-

Tabela 4 - Médias estimadas da avaliação das características físicas de carcaça de leitoas, de acordo com os planos de nutrição

Table 4 - Estimated means of the carcass physical evaluation characteristics of gilts, according to the nutrition plans

\begin{tabular}{|c|c|c|c|c|c|}
\hline \multirow{3}{*}{$\begin{array}{l}\text { Parâmetro } \\
\text { Parameter }\end{array}$} & \multicolumn{4}{|c|}{$\begin{array}{c}\text { Planos de nutrição (níveis de lisina, \%) } \\
\text { Nutrition plans - lysine levels }\end{array}$} & \multirow{3}{*}{$\begin{array}{l}\mathrm{CV} \\
\%\end{array}$} \\
\hline & 1 & 2 & 3 & 4 & \\
\hline & $(0,80-0,70)$ & $(0,90-0,80)$ & $(1,00-0,90)$ & $(1,10-1,00)$ & \\
\hline $\mathrm{CCMB}^{*}(\mathrm{~cm})$ & 98,43 & 98,44 & 99,67 & 99,46 & 3,42 \\
\hline $\mathrm{ET}^{* *}(\mathrm{~mm})$ & $21,91^{\mathrm{a}}$ & $19,75^{\mathrm{ab}}$ & $19,00^{\mathrm{b}}$ & $18,40^{\mathrm{b}}$ & 13,11 \\
\hline $\mathrm{P}_{2}{ }^{* * *}(\mathrm{~mm})$ & $12,54^{\mathrm{a}}$ & $11,50^{\mathrm{ab}}$ & $9,75^{\mathrm{C}}$ & $10,80^{\mathrm{bc}}$ & 12,62 \\
\hline $\mathrm{RC}(\%)$ & 81,77 & 83,95 & 83,38 & 83,42 & 1,93 \\
\hline RCM(\%) & 59,49 & 58,34 & 59,43 & 59,37 & 2,21 \\
\hline RG(\%) & 20,24 & 20,33 & 19,96 & 19,75 & 10,53 \\
\hline $\mathrm{RP}(\%)$ & 31,01 & 33,26 & 32,02 & 32,44 & 4,73 \\
\hline $\mathrm{AOL}(\mathrm{cm})$ & $42,34^{b}$ & $45,90^{\mathrm{a}}$ & $45,59^{a}$ & $44,74^{\mathrm{a}}$ & 1,61 \\
\hline \multicolumn{6}{|c|}{$\begin{array}{l}\text { Médias na mesma linha, seguidas de letras diferentes, diferem pelo teste } F(P<0,01) \text { (Means within a row, followed by different letters, differ } \\
\text { by } F \text { test }[P<.01]) \text {. } \\
\text { * Comprimento de carcaça pelo método brasileiro de classificação de carcaça (Carcass length measured by the Brazilian method of carcass } \\
\text { classification). } \\
\text { Espessura de toucinho na região entre a última e a penúltima vértebra lombar (Backfat thickness in the region between the last and the last } \\
\text { but one lumbar vertebra). } \\
\text { Espessura de toucinho a } 6,5 \mathrm{~cm} \text { da linha dorso-lombar (Backfat thickness at } 6.5 \mathrm{~cm} \text { from the midline of carcass). } \\
\text { RC - Rendimento de carcaça (Carcass yield). } \\
\text { RCM - Rendimento de carne magra (lean meat yield). } \\
\text { RG - Rendimento de gordura (Fat yield). } \\
\text { RP - Rendimento de pernil (Ham yield). } \\
\text { AOL - Área de olho de lombo (Loin eye area). }\end{array}$} \\
\hline
\end{tabular}

R. Bras. Zootec., v.32, n.6, p.1330-1338, 2003 
cas de carcaça. Entretanto, Gonçalves et al. (1999), avaliando planos de nutrição para suínos em crescimento e terminação, com alto potencial genético para produção de carne magra, encontraram que o plano de nutrição com os menores níveis de lisina, 0,85 e 0,60\%, respectivamente, para as fases de crescimento e terminação, resultou na produção de carcaças mais compridas.

Quanto ao RC, esperava-se efeito dos planos de nutrição, uma vez que essa característica, segundo Bereskin \& Davey (1976) e Oliveira (1988), é influenciada, geralmente, pelo melhoramento para produção de carne a que uma determinada linhagem é submetida, e, com o aumento da quantidade de carne, há uma tendência de redução no rendimento de carcaça. Da mesma forma, Friesen et al. (1994) mostraram que a elevação no RC resulta em redução de carne e aumento de gordura.

As outras características que fornecem indicativo da quantidade de carne e de gordura presente no animal, avaliadas nesse experimento, foram as medidas de espessura de toucinho (ET e P2), o rendimento de carna magra (RCM), o rendimento de gordura (RG), o rendimento de pernil (RP) e a área de olho de lombo (AOL). Com relação à medida de P2, constatou-se que as carcaças dos animais que receberam o plano de nutrição 3 (1,00\% - 0,90\%), não diferiram $(\mathrm{P}>0,05)$ das carcaças dos animais do plano 4 (1,10\% - 1,00\%), sendo, no entanto, menor $(\mathrm{P}<0,01)$ que os planos $1(0,80 \%-0,70 \%)$ e $2(0,90 \%$ - 0,80\%). Comportamento semelhante foi observado para a medida de ET, em que os animais que receberam o plano 3 obtiveram menor $(\mathrm{P}<0,01)$ espessura de toucinho que o plano 1, não diferindo dos demais (planos 2 e 4). Gonçalves et al. (1999), utilizando diferentes planos de nutrição em função dos níveis de lisina ( 0,85 e $0,60 \% ; 1,00$ e $0,75 \% ; 1,15$ e $0,90 \%)$ na ração, para suínos em crescimento e terminação, observaram menor deposição de gordura (P2) nas carcaças dos animais que receberam o plano correspondente aos níveis de 0,85 e $0,60 \%$ de lisina total.

O RCM e o RG, obtidos neste experimento, não foram influenciados pelos planos de nutrição, vindo confirmar os resultados obtidos por Grandhi \& Cliplet (1997) e Souza Filho et al. (1998) para suínos de elevado potencial genético para deposição de carne magra, abatidos aos 130 e $105 \mathrm{~kg}$, respectivamente. Contrariamente, Oliveira (2001) constatou redução linear no rendimento de gordura com o aumento dos níveis de lisina da ração, utilizando suínos machos castrados de elevado potencial genético para deposi- ção de carne magra, dos 95 aos 110 kg.

Não houve efeito dos planos de nutrição sobre o RP. Este resultado está de acordo com os de Fialho et al. (1998), Gomes (1998) e Gonçalves et al. (1999) e discordante dos obtidos por Friesen et al. (1994), Chen et al. (1995) e Irvin et al. (1995).

Embora não tenha sido observada diferença $(\mathrm{P}>0,05)$ entre os planos avaliados neste trabalho, $\mathrm{O}$ $\mathrm{RP}$ dos animais que receberam os menores níveis de lisina (plano de nutrição 1) foi de 3,27 a 7,26\% menor em relação aos demais planos de nutrição.

Quanto a AOL, foi observado que os planos de nutrição 2, 3 e 4, que não diferiram $(P>0,05)$ entre si, foram superiores $(\mathrm{P}<0,01)$ ao plano 1 .

Coffey et al. (1994), em uma revisão de estudo sobre o efeito do nível delisina na ração, no desempenho e características de carcaça de machos castrados e fêmeas, dos 51 aos $105 \mathrm{~kg}$, demonstraram que o aumento do nível de lisina, de 0,58 para $0,80 \%$, não afetou a AOL dos machos castrados, mas resultou em aumento de 9\% na AOL da carcaça das fêmeas. Em contrapartida, Friesen et al. (1994), Grandhi \& Cliplet (1997), Souza Filho (1999), Gonçalves et al. (1999) e Oliveira (2001) não observaram efeito do nível de lisina sobre a AOL de suínos em terminação.

Estes resultados diferem dos obtidos em outros trabalhos (Cristian et al., 1980; Stahly, 1993; Friesen et al., 1994; Chen et al., 1995), que mostraram maior exigência de lisina para a deposição de tecido muscular, evidenciando forte tendência na melhoria das características de carcaça dos suínos.

O valor médio da AOL, de 44,64 cm2, determinado neste trabalho, foi superior aos valores médios de 37,2; 38, 6; 31,3; 40,1 e 40,0 cm2 encontrados, respectivamente, por Friesen et al. (1995), Hahn et al. (1995), Grandhi \& Cliplef (1997), Gonçalves et al. (1999) e Oliveira (2001).

É possível que a variação ocorrida nos resultados de AOL, nos diversos trabalhos, tenha sido causada pela diferença na capacidade genética de deposição de carne magra na carcaça dos animais utilizados, conforme relatado por Wagner et al. (1999) em que constataram variação de 27,68 a 35,61 cm2 na AOL de cinco populações genéticas de suínos dos 25 aos $152 \mathrm{~kg}$.

Os resultados da análise econômica dos diferentes planos de nutrição são apresentados na Tabela 5.

O índice de rentabilidade determina a taxa de retorno sobre os custos, isto é, o retorno líquido de cada unidade monetária gasta nas despesas incorridas na produção. 
Tabela 5 - Índice de rentabilidade para cada plano de nutrição em razão dos níveis de lisina avaliados Table 5 - Profit index for each nutrition plan, according to the nutrition plans

\begin{tabular}{lccc}
\hline $\begin{array}{l}\text { Planos de nutrição (Níveis de lisina, \%) } \\
\text { Nutrition plans (Lysine levels, \%) }\end{array}$ & \multicolumn{2}{c}{$\begin{array}{c}\text { Custo da ração (R \$/kg) } \\
\text { Diet cost }\end{array}$} & $\begin{array}{c}\text { Índice de rentabilidade (IR) } \\
\text { Profit index }\end{array}$ \\
\cline { 2 - 3 } & $\begin{array}{c}\text { Terminação I } \\
\text { Finishing I }\end{array}$ & $\begin{array}{c}\text { Terminação II } \\
\text { Finishing II }\end{array}$ \\
\hline PLANO 1 (0,80-0,70) & 0,187 & 0,183 & 0,37 \\
PLANO 2 (0,90-0,80) & 0,191 & 0,187 & 0,60 \\
PLANO3 (1,00-0,90) & 0,195 & 0,191 & 0,60 \\
PLANO4 4 (1,10-1,00) & 0,200 & 0,195 & 0,54 \\
\hline
\end{tabular}

É importante salientar que o índice de rentabilidade adotado mostra o retorno do capital investido na ração. Os outros componentes do custo de produção não foram, a priori, incluídos na análise, sendo considerados os mesmos para todos os tratamentos.

O estudo da análise econômica indicou que os animais, que consumiram as rações dos planos de nutrição 2 e 3, obtiveram iguais índices de rentabilidade $(0,60)$ que foram superiores aos dos demais planos, resultando, para cada $\mathrm{R} \$ 1,00$ gasto com a formulação das rações, em uma receita líquida de $\mathrm{R} \$ 0,60$, desconsiderando-se os demais custos

incorridos na produção. A rentabilidade dos planos 2 e 3 foi superior a 0,23 centavos de real em relação ao plano 1 , superando também o plano 4, em 0,06 centavos de real.

Com base nos resultados obtidos pode-se deduzir que o plano de nutrição 3, correspondente aos níveis de lisina de 1,00-0,90\%, por ter proporcionado as melhores respostas de conversão alimentar, taxa de crescimento de músculo, menor espessura de toucinho no P2, além de um dos maiores retornos econômicos entre os planos avaliados, corresponde à exigência dos animais.

\section{Conclusões}

Leitoas com alto potencial para deposição de carne magra na carcaça exigem, para melhor conversão alimentar, taxa de crescimento em músculo e características de carcaça, 1,00 e 0,90\% de lisina total, respectivamente, para as faixas de peso de 65 a $95 \mathrm{~kg}$ e de 95 a $105 \mathrm{~kg}$.

\section{Literatura Citada}

ALMEIDA NETO, P.P.; OLIVEIRA, A.I.G.; ALMEIDA, A.J.L. et al. Parâmetros genéticos e fenotípicos de características de carcaça de suínos. Revista Brasileira de Zootecnia, v.22, n.4, p.624-633, 1993.
ASSOCIAÇÃO BRASILEIRA DE CRIADORES DE SUÍNOS - ABCS. Método Brasileiro de Classificação de Carcaça. Estrela, RS, 1973. 17p.

BELLAVER, C.; VIOLA, E.S. Qualidade de carcaça, nutrição e manejo nutricional. In: VIII CONGRESSO BRASILEIRO DE VETERINÁRIOS ESPECIALISTAS EM SUÍNOS, 1997, Foz do Iguaçu. Anais... Foz do Iguaçu: ABRAVES, 1997. p.152-158.

BERESKIN, B.J.; DAVEY, R.J. Breed, line, sex and diet effects and interaction in swine carcass traits. Journal of Animal Science, v.42, n.1, p.43-51, 1976.

BUARQUE, C. Avaliação econômica de projetos: uma apresentação didática. Rio de Janeiro: Campus, 8.ed. 1991.

CATALAN, G. Estimativas de parâmetros genéticos e fenotípicos em suínos Landrace, Large White e Duroc, nas fases de crescimento e terminação. Viçosa, MG: Universidade Federal de Viçosa, 1986. 129p. Dissertação (Mestrado em Zootecnia) - Universidade Federal de Viçosa, 1986.

CHEN, H.Y.; MILLER, T.S.; LEWIS, A.J. et al. Changes in plasma urea concentration can be used to determine protein requirements of two populations of pigs with different protein acretion rates. Journal of Animal Science, v.73, n.9, p.2631-2639, 1995.

CHEN, H.Y.; LEWIS, A.J.; MILLER, P.S. et al. The effect of excess protein on growth performance and protein metabolism of finishing barrows and gilts. Journal of Animal Science, v.77, p.3238-3247, 1999.

COFFEY, R.D.; PARKER, G.R.; LAURENT, K.M. Feeding growing-finishing pigs to maximize lean growth rate. Cooperative Extension Service. University of Kentucky, College of Agricluture. ASC-147. 1994.

CROMWELL, G.L.; CLINE, T.R.; CRENSHAW, J.D. et al. The dietary protein and (or) lysine requirements of barrows and gilts. Journal of Animal Science, v.71, n.6, p.1510-1519, 1993.

DONZELE, J.L.; FREITAS, R.T.F.; OLIVEIRA, R.F.M. et al. Níveis de lisina para leitoas de 30 a $60 \mathrm{~kg}$ de peso vivo. Revista da Sociedade Brasileira de Zootecnia, v.24, n.6, p.967-973, 1994.

EASTER, R.A.; BAKER, D.H. Lysine and protein level in cornsoybean meal diets for growing swine. Journal of Animal Science, v.50, n.3, p.467-471, 1980.

FIALHO, E.T.; OLIVEIRA, A.I.G.; LIMA, J.A.F. et al. Influência de planos de nutrição sobre as características de carcaça de suínos de diferentes genótipos abatidos entre 80 e 120 kg. Revista Brasileira de Zootecnia, v.27, n.6, p.1140-1146, 1998.

FONTES, D.O. Lisina para leitoas selecionadas genetica- 
mente para deposição de carne magra na carcaça, dos 15 aos 90 kg. Viçosa, MG: Universidade Federal de Viçosa, 1999. 101p. Tese (Doutorado em Zootecnia) - Universidade Federal de Viçosa, 1999.

FOWLER, V.R.; BICHARD, M.; PEASE, A. Objectives in pig breeding. Animal Production, v.23, n.3, p.365-387, 1976.

FRIESEN, K.G.; NELSSEN, J.L.; GOODBAND, R.D. et al. Influence of dietary lysine on growth and carcass composition of high-lean-growth gilts fed from 34 to 72 kilograms. Journal of Animal Science, v.72, p.1761-1770, 1994.

FRIESEN, K.G.; NELSSEN, J.L.; GOODBAND, R.D. et al. The effect of dietary lysine on growth, carcass composition, and lipid metabolism in high-lean growth gilts fed from 72 to 136 kilograms. Journal of Animal Science, v.73, p.3392-3401, 1995.

FULLER, M. Macronutrient requirements of growing swine. In: SIMPÓSIO INTERNACIONAL SOBRE EXIGÊNCIAS NUTRICIONAIS DE AVES E SUÍNOS, 1996, Viçosa, MG. Anais... Viçosa: Universidade Federal de Viçosa, 1996.

GOMES, F.E. Planos de nutrição baseados em níveis de lisina para suínos de diferentes genótipos abatidos aos 80 e 100 kg de peso vivo. Lavras, MG: Universidade Federal de Lavras, 1998. 55p. Dissertação (Mestrado em Zootecnia) - Universidade Federal de Lavras, 1998.

GONÇALVES, T.M.; BERTECHINI, A.G.; OLIVEIRA, I.G. et al. Lisina, energia e sexo sobre as características de carcaça de suínos híbridos modernos. In: CONGRESSO BRASILEIRO DE ZOOTECNIA, 36., 1999, Porto Alegre-RS. Anais... Porto Alegre: SBZ, 1999. (CD-ROM).

GU, Y.; SCHINCKEL, A.P.; FOREST, J.P. et al. Effects of ractopamine, genotype, and growth phase on finishing performance and carcass value in swine. II. Estimation of lean growth rate and leaned feed efficiency. Journal of Animal Science, v.69, n.1, p.2694-2702, 1991.

HAMMELL, K.L.; LAFOREST, J.P.; DUFOUR, J.J. Evaluation of the growing performance and carcass characteristics of commercial pigs produced in Quebec. Canadian Journal of Animal Science, v.73, n.3, p.495-508, 1993.

HANSEN, B.C.; LEWIS, A.J. Effects of dietary protein concentration (corn, soybean meal ratio) on the performance and carcass characteristics of growing boar, barrows and gilts: mathematical descriptions. Journal of Animal Science, v.71, n.8, p.2122-2123, 1993.

HERNÁNDEZ VILLARREAL, L.A. Planos de nutrição influenciando as características de carcaça de suínos. Lavras: Universidade Federal de Lavras, 1996. 58p. Dissertação (Mestrado em Zootecnia) - Universidade Federal de Lavras, 1996.

IRVIN, K.M.; SWIGER, L.A.; MAHAN, D.C. Influence of dietary-protein level on swine with different growth capabilities. Journal of Animal Science, v.73, n.5, p.10311047, 1995.

LAURENCE, B.V.; ADEOLA, O.; CLINE, T. R. Lean growth response of pigs fed diets balanced on a lysine to digestible energy basis from 50 to $110 \mathrm{~kg}$. Journal of Animal Science, v.72, p.216 (Suppl. 1), 1994a.

MARINHO, S.F. Exigência nutricional de lisina e avaliação de rações formuladas com valores de lisina total e digestível para suínos em terminação. Viçosa, MG:UFV, 1990. 81 p. Dissertação (Mestrado em Zootecnia) - Universidade Federal de Viçosa, 1990.

NATIONAL RESEARCH COUNCIL - NRC. Nutrient requirements of swine. 10.ed., Washington, D.C.: National Academic of Sciences, 1998. 189p.
OLIVEIRA, A.L.S. Níveis de lisina para suínos machos castrados de alto potencial genético para deposição de carne magra dos 95 aos 125 kg. Viçosa, MG: Universidade Federal de Viçosa, 2001. 42p. Dissertação (Mestrado em Zootecnia) - Universidade Federal de Viçosa, 2001.

OLIVEIRA, A.I.G.; SILVA, M.A.; TEIXEIRA, N.M. et al. Aspectos genéticos das características físicas das carcaças de suínos em cruzamentos dialéticos. II. Características de classificação. Revista Brasileira de Zootecnia, v.17, n.6, p.535-543, 1988.

PIMENTA, M.E.S.G. Planos de nutrição para suínos de dois genótipos com pesos diferentes de abate. Lavras, MG: Universidade Federal de Lavras, 1995. 66p. Dissertação(Mestrado em Zootecnia) - Universidade Federal de Lavras, 1995.

ROSTAGNO, H.S.; SILVA, D.J.; COSTA, P.M.A. et al. Composição de alimentos e exigências nutricionais de aves e suínos (Tabelas brasileiras). Viçosa, MG: Universidade Federal de Viçosa, 1992. 59p.

SAENZ, E.A.C. Aplicação de modelos animais na estimação de parâmetros genéticos em características de carcaças de suínos. Lavras: Universidade Federal de Lavras, 1994. 57p. Dissertação (Mestrado em Zootecnia) - Universidade Federal de Lavras, 1994.

SAS Institute Inc. Introductory guide for personal computer. Version 6.ed., Cary: 1985. 111p.

SCHUTTE, J.B.; Van WEERDEN, E.J. Interaction between lysine and SAA, threonine and tryptophan in pigs in the live weight period of 10-30 kg. Report LBO-TNO, n.552. 1985.

SILVA, I.J.O. Sistemas naturais e artificiais do controle do ambiente-Climatização. In: SILVA, I.J.O. (Ed.) Ambiência e qualidade na produção industrial de suínos. Piracicaba: Fundação de Estudos Agrários Luiz de Queiroz, 1999. 247p.

SOUZA, A.M. Exigências nutricionais de lisina para suínos mestiços, de 15 a 95 kg de peso. Viçosa, MG: Universidade Federal de Viçosa, 1997. 81p. Dissertação (Mestrado em Zootecnia) - Universidade Federal de Viçosa, 1997.

SOUZA FILHO, G.A.; LIMA, J.A.F.; FIALHO, E.T. et al. Efeito de planos de nutrição e de genótipos sobre características físicas de carcaça de suínos. In: In: REUNIÃO ANUAL DA SOCIEDADE BRASILEIRA DE ZOOTECNIA, 36., 1999, Porto Alegre. Anais... Porto Alegre: Sociedade Brasileira de Zootecnia, 1999. CD ROM

STAHLY, T.S.; CROMWELL, G.L.; TERHUNE, D. Responses of pigs from high and low lean growth genotypes to dietary lysine levels. Journal of Animal Science, v.66 (Suppl. 1), p.137 (Abstr.), 1988.

STAHLY, T.S.; CROMWELL, G.L.; TERHUME, D. Responses of high, medium and low lean growth genotypes to dietary amino acid regimen. Journal of Animal Science, v.69 (suppl. 1), p.364 (Abstr.), 1991.

STAHLY, T. Nutrition effects lean growth, carcass composition. Feedstuffs, v.65, n.26, p.12, 1993.

STAHLY, T.S.; WILLIAMS, N.H.; SWENSON, S. Impact of genotype and dietary amino acid regimen on growth of pigs from 6 to $25 \mathrm{~kg}$. Journal of Animal Science, v.69, p.165, 1994. (Suppl. 1)

YEN, J.P.; KLINDT, J.; KERR, B.J. et al. Lysine requirement in finishing pigs treated with porcine somatotropin by sustainedrelease implant. Journal of Animal Science, v.74, p.196, 1996. (Suppl. 1)

Recebido em: 02/10/01 Aceito em: 05/03/03 